\title{
The role of impaired brain perfusion in septic encephalopathy
}

\author{
Lucia Rivera-Lara ${ }^{1,2}$ (D) \\ See related research by Crippa et al., https://ccforum.biomedcentral.com/articles/10.1186/s13054-018-2258-8.
}

Sepsis-associated encephalopathy (SAE), also known as sepsis-associated brain dysfunction (SABD) or sepsis-associated delirium, is an acute condition that has been reported to affect up to $76 \%$ of patients with sepsis [1]. Furthermore, patients with SAE have higher in-hospital mortality than do patients who have sepsis without SAE $(62.4 \%$ versus $23.4 \%, P<0.0001)[2,3]$.

For decades, it has been thought that the brain dysfunction in SAE is a consequence of the inflammatory response to a systemic infection; however, evidence indicates that sepsis survivors have long-term cognitive impairment, lower quality of life, and structural brain lesions that include hippocampal atrophy, white matter disease, and ischemic strokes [4-6]. These long-term sequelae suggest that SAE may be secondary to microcirculatory dysfunction in the brain with insufficient blood supply. A study in animals showed that somatosensory amplitudes and related evoked flow velocity responses decreased in rats with severe sepsis when cerebral hyperemia was just beginning to develop. The activation flow coupling was impaired in severe sepsis, and the decrease in evoked flow velocity preceded that of somatosensory amplitudes by nearly $2 \mathrm{~h}$, suggesting inappropriate blood supply of the activated brain area [7]. Furthermore, in a prospective study of 112 patients with sepsis, Yao et al. [3] compared brain injury biomarker levels in patients who did and those who did not develop SAE. The authors found that both S100b and neuron-specific enolase were significantly higher in patients with SAE than in those without SAE. These results suggest possible neuronal and glial injury during SAE that could be secondary to hypoperfusion.

Impaired cerebral autoregulation (CA) has also been reported in up to $60 \%$ of patients with sepsis on day 1 ;

\footnotetext{
Correspondence: Iriver14@jhmi.edu
}

${ }^{1}$ Department of Neurology, The Johns Hopkins University School of Medicine, 600 N Wolfe Street, Phipps 455, Baltimore, MD 21287, USA ${ }^{2}$ Department of Anesthesiology and Critical Care Medicine, The Johns Hopkins University School of Medicine, 600 N Wolfe Street, Phipps 455, Baltimore, MD 21287, USA

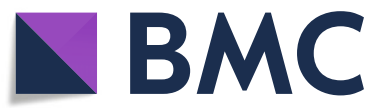

(c) The Author(s). 2019 Open Access This article is distributed under the terms of the Creative Commons Attribution 4.0 International License (http://creativecommons.org/licenses/by/4.0/), which permits unrestricted use, distribution, and reproduction in any medium, provided you give appropriate credit to the original author(s) and the source, provide a link to the Creative Commons license, and indicate if changes were made. The Creative Commons Public Domain Dedication waiver (http://creativecommons.org/publicdomain/zero/1.0/) applies to the data made available in this article, unless otherwise stated. interestingly, impaired $\mathrm{CA}$ at day 1 is associated with SAE at day 4 [1]. A recent study published in Critical Care with a larger sample size re-emphasizes this issue. Crippa and co-authors completed a prospective study of 100 patients with sepsis in two European intensive care units (ICUs). The aim of this study was to evaluate the association between altered $\mathrm{CA}$ and the occurrence of SABD. CA was measured by using transcranial Doppler. Mxa was calculated with MATLAB (MathWorks, Natick, MA, USA) as the Pearson's correlation coefficient between the averaged mean arterial pressure (MAP) and flow velocity. Patients were monitored for only $10 \mathrm{~min}$, $48 \mathrm{~h}$ after diagnosis of sepsis. In this study, $50 \%$ of patients had impaired CA. SABD was diagnosed in 57\% of patients, and those with SABD had longer ICU length of stay and greater ICU mortality than patients without SABD. SABD was more common in patients with altered CA than in those with intact CA.

Prior studies of $\mathrm{CA}$ in sepsis have included rather small numbers of patients $(<40)$; however, they have shown a consistent pattern in which patients with SAE have more impaired CA than those patients without it $[1,8,9]$. Impairment of CA in sepsis likely has two causes. The first occurs when MAP falls below the patient's lower limit of CA. Modern data on autoregulation in adults have shown that the lower limits of autoregulation may vary from 40 to $90 \mathrm{~mm} \mathrm{Hg}$ [10]. A recent study investigating higher blood pressure targets for patients with septic shock showed that the subset of patients with chronic hypertension randomly assigned to the higher MAP goal of 80 to $85 \mathrm{~mm} \mathrm{Hg}$ required less renal replacement therapy than similar patients who were randomly assigned to the MAP goal of 65 to $70 \mathrm{~mm} \mathrm{Hg}$ [11]. The latter study suggests that when MAP has dropped below the lower limit of CA, renal perfusion is also at risk. This link between kidney and brain autoregulation has been proposed before [12].

The second reason for impaired CA in sepsis, and actually the major confounder when monitoring cerebral 
hemodynamics in patients with sepsis, is the vascular dysfunction triggered by the systemic inflammatory process. Disruption of the blood-brain barrier, nitric oxide accumulation, and microvascular damage are only some potential causes [13-15]. Taccone et al. [13] found that, in septic animals, cerebral functional capillary density and the proportion of small perfused vessels decreased significantly at the onset of septic shock when compared with non-septic animals. Concomitantly, brain oxygen tension $\left(\mathrm{PbO}_{2}\right)$ decreased and lactate/pyruvate ratio increased. At $18 \mathrm{~h}$, when shock was present, animals with MAP of less than $65 \mathrm{~mm} \mathrm{Hg}(\mathrm{n}=6)$ had similar functional capillary density, proportion of small perfused vessels, and $\mathrm{PbO}_{2}$ values but a significantly higher lactate/pyruvate ratio when compared with animals whose MAP was $65-70$ $\mathrm{mm} \mathrm{Hg}(\mathrm{n}=4)$ [13]. Therefore, both of these alterations (systemic inflammatory process and hypotension) likely play an important role in the pathogenesis of brain dysfunction during sepsis.

To move forward and find the true answer to the question of whether SAE is a consequence of brain hypoperfusion secondary to impaired CA, future studies need to standardize definitions of brain dysfunction, delirium, and encephalopathy in the ICU. Second, a more comprehensive set of neuromonitoring tools should be applied to study the cerebral hemodynamics in these patients. Lastly, we need to study the brain more comprehensively, as SAE is a diagnosis of exclusion. Therefore, we need brain imaging and complete neurological assessments to rule out other brain disorders.

\section{Abbreviations}

CA: Cerebral autoregulation; ICU: Intensive care unit; MAP: Mean arterial pressure; $\mathrm{PbO}_{2}$ : Brain oxygen tension; SABD: Sepsis-associated brain dysfunction; SAE: Sepsis-associated encephalopathy

\section{Funding}

LR-L was awarded a grant from Medtronic/Covidien (Dublin, Ireland) and Ornim Medical, Inc. (Foxborough, MA, USA). She is also the principal investigator on a Stimulating and Advancing ACCM Research (StAAR) grant from the Department of Anesthesiology and Critical Care Medicine of Johns Hopkins University.

\section{Availability of data and materials}

Not applicable.

\section{Author's contributions}

The author read and approved the final manuscript.

Ethics approval and consent to participate

Not applicable.

\section{Consent for publication}

Not applicable.

\section{Competing interests}

The author declares that she has no competing interests.
Received: 13 November 2018 Accepted: 21 December 2018

Published online: 19 February 2019

\section{References}

1. Schramm P, Klein KU, Falkenberg L, Berres M, Closhen D, Werhahn K, et al. Impaired cerebrovascular autoregulation in patients with severe sepsis and sepsis-associated delirium. Crit Care. 2012;16:R181.

2. Zhang LN, Wang XT, Ai YH, Guo QL, Huang L, Liu ZY, et al. Epidemiological features and risk factors of sepsis-associated encephalopathy in intensive care unit patients: 2008-2011. Chin Med J. 2012;125:828-31.

3. Yao B, Zhang LN, Ai YH, Liu ZY, Huang L. Serum S100beta is a better biomarker than neuron-specific enolase for sepsis-associated encephalopathy and determining its prognosis: a prospective and observational study. Neurochem Res. 2014;39:1263-9.

4. Semmler A, Widmann CN, Okulla T, Urbach H, Kaiser M, Widman G, et al. Persistent cognitive impairment, hippocampal atrophy and EEG changes in sepsis survivors. J Neurol Neurosurg Psychiatry. 2013;84:62-9.

5. Comim CM, Constantino LC, Barichello T, Streck EL, Quevedo J, Dal-Pizzol F. Cognitive impairment in the septic brain. Curr Neurovasc Res. 2009;6:194-203.

6. Sharshar T, Carlier R, Bernard F, Guidoux C, Brouland JP, Nardi O, et al. Brain lesions in septic shock: a magnetic resonance imaging study. Intensive Care Med. 2007:33:798-806.

7. Rosengarten $B$, Hecht M, Auch D, Ghofrani HA, Schermuly RT, Grimminger F, et al. Microcirculatory dysfunction in the brain precedes changes in evoked potentials in endotoxin-induced sepsis syndrome in rats. Cerebrovasc Dis. 2007:23:140-7.

8. Berg RM, Plovsing RR, Ronit A, Bailey DM, Holstein-Rathlou NH, Moller K. Disassociation of static and dynamic cerebral autoregulatory performance in healthy volunteers after lipopolysaccharide infusion and in patients with sepsis. Am J Physiol Regul Integr Comp Physiol. 2012;303:R1127-35.

9. Pierrakos C, Attou R, Decorte L, Kolyviras A, Malinverni S, Gottignies P, et al. Transcranial Doppler to assess sepsis-associated encephalopathy in critically ill patients. BMC Anesthesiol. 2014;14:45

10. Joshi B, Ono M, Brown C, Brady K, Easley RB, Yenokyan G, et al. Predicting the limits of cerebral autoregulation during cardiopulmonary bypass. Anesth Analg. 2012;114:503-10.

11. Asfar P, Meziani F, Hamel JF, Grelon F, Megarbane B, Anguel N, et al. High versus low blood-pressure target in patients with septic shock. N Engl J Med. 2014;370:1583-93.

12. Prough DS, Esenaliev R. Monitoring the brain to save the kidneys. Crit Care Med. 2013:41:671-2.

13. Taccone FS, Su F, Pierrakos C, He X, James S, Dewitte O, et al. Cerebral microcirculation is impaired during sepsis: an experimental study. Crit Care. 2010;14:R140.

14. Lavi S, Egbarya R, Lavi R, Jacob G. Role of nitric oxide in the regulation of cerebral blood flow in humans: chemoregulation versus mechanoregulation. Circulation. 2003;107:1901-5.

15. Tsao N, Hsu HP, Wu CM, Liu CC, Lei HY. Tumour necrosis factor-alpha causes an increase in blood-brain barrier permeability during sepsis. J Med Microbiol. 2001;50:812-21.

\section{Publisher's Note}

Springer Nature remains neutral with regard to jurisdictional claims in published maps and institutional affiliations. 